\title{
An Investigation on Vortex Breakdown Phenomena in a Vertical Cylindrical Tube
}

\author{
Nazih. N. Bayomi, Mohamed. H. Said*, Momtaz. F. Sedrak** and \\ Abd El - Nabi Z. El - Syed*** \\ King Abdulaziz University, Jeddah, Saudi Arabia, *Faculty of Industrial \\ Education, Helwan University, **Faculty of Eng., Egyptian Russian University, \\ ***High Institute of Engineering, Shorouk Academy, Cairo, Egypt. \\ nnbayomi@hotmail.com
}

\begin{abstract}
Vortex flows are subject to a number of major structural changes involving very large disturbances when a characteristic ratio of azimuthal to axial velocity components is varied. Vortex breakdowns are among the structural forms that may occur. This phenomenon is one of the hydrodynamic instability problems and it is encountered in many practical application, such as, aerodynamics (in aeronautics), combustion chamber, diffusers and nozzle.

The objectives of the present research are to investigate the effect of Reynolds number (Re) and circulation number $(\Omega)$ on the observed modes of the vortex breakdown. The position of the vortex breakdown with two vertical cylinder tube length as well as for clockwise and anti-clockwise flow direction is also investigated.

The results revealed that there are a total of six distinct modes of the disruption of the vortex core as $\operatorname{Re}$ and $\Omega$ of the flow were varied. The breakdown position was found to be dependent on both $\mathrm{Re}$ and $\Omega$ of the flow. Whereas, for all Re values an increase in $\Omega$ always results in moving the breakdown position upstream for all $\mathrm{Re}$ values. The breakdown position is smaller for anti-clockwise flow direction than that, when vanes were set at clockwise flow direction for long and short tube.
\end{abstract}

\section{Introduction}

The term "vortex breakdown" or "vortex bursting" is used to denote the abrupt disorganization of a slender vortex that occurs when a characteristic ratio of azimuthally to axial velocity components is varied. The defining features of the phenomenon include the very pronounced 
deceleration of the stream wise flow along the axis of the vortex accompanied by radial divergence of the stream surfaces, Hall ${ }^{[1]}$. The resulting intense axial flow gradients can lead to the formation of an internal stagnation point on the vortex axis, followed by reversed flow in a region of limited axial extent, Leibovich ${ }^{[2]}$. Depending on the Reynolds number based on the tube diameter, Re, and the intensity of the swirling motion, the vortex core immediately downstream of the breakdown region is known to undergo remarkable transformations, which in most cases, are characterized by unsteady, three dimensional fluctuations, Sarpkaya $^{[3-4]}$, Faler and Leibovich ${ }^{[5]}$, Garg \& Leibovich ${ }^{[6]}$ Leibovich $^{[7]}$, and Lucca-Negro \& O"Doherty ${ }^{[8]}$.

The possibility of breakdown is a remarkable behavior of vortex cores. Within many vortex flows a core of high vorticity can be found that is at least roughly axisymmetric. There is characteristically, an appreciable axial compound of motion in addition to the swirl, or azimuthally component. Such a vortex core is readily set up by passing a fluid through a pipe and imparting swirl with a set of vanes at entry. The phenomenon is of crucial significance in several devices of technological importance, such as delta wings (aircraft), Peckham and Atkinson ${ }^{[9]}$, Srigrarom \& Rizwan ${ }^{[10]}$, Srigrarom \& Lewpiriyawong ${ }^{[11]}$, draft tube of hydraulic turbines, Sharma et al. ${ }^{[12]}$, and Cervants ${ }^{[13]}$ and swirling combustors, Stein \& Kempf ${ }^{[14]}$ and Tangermann \& Pfitzner ${ }^{[15]}$. Aksel \& kaya $^{[16]}$ and Jochmann ${ }^{[17]}$ gave numerical computations of the vortex breakdown phenomenon taking place in a cylinder.

Under controlled phenomenon circumstances, experiments on vortices confined in tubes were devised by Harvey ${ }^{[18-19]}$, Sarpkaya ${ }^{[3]}$, Bellamy Knights ${ }^{[20]}$, Faler and Leibovich ${ }^{[5-21]}$, Bayomi ${ }^{[22]}$ and Heikal et $a l .{ }^{[23]}$, Althaus et al. ${ }^{[24]}$, Hourigan et al. ${ }^{[25]}$, Bhattachavyya \& $\mathrm{Pal}^{[26]}$, Hussain et al. ${ }^{[27]}$ and Said ${ }^{[28]}$, and so many others. Most investigators used a horizontal divergent tube as a test section to study the different modes of vortex breakdown phenomena but Harvey ${ }^{[19]}$ and Bayomi ${ }^{[22]}$ used constant diameter vertical cylindrical tube. In all these papers the pipe length was fixed and unchanged and some of them used only one direction for flow swirl.

Also, despite the extensive experimental, numerical and theoretical research, the phenomenon of vortex breakdown remains controversial and no generally accepted explanation has emerged. 
The aim of the present investigation is to study the dependence of the vortex core disruption modes and its position on the Reynolds number $(\mathrm{Re})$ and circulation number $(\Omega)$ in a vertical cylindrical tube with constant diameter of $5 \mathrm{~cm}$, for two tube lengths of $(\mathrm{L}=60 \mathrm{~cm}$ and $\mathrm{L}$ $=120 \mathrm{~cm})$ as well as for clockwise and anti-clockwise flow direction. Water is used as a working fluid and dye injection was used for flow visualization.

\section{Experimental Setup and Test Procedures}

The objectives of the following experimental work are studying the effect of the Reynolds number and amount of swirl imparted on the fluid as well as the direction of the swirl on the type and the position of the vortex breakdown with vertical two tube length (downstream effect). To verify these requirements, a special test rig has been designed and constructed in fluid mechanics laboratory, Faculty of Engineering, Mataria, Helwan University. A schematic diagram of the test rig is given in Fig. 1 (a). Figure 1 (a) shows the main components of the test rig which consists of feed water pump (1), rotameter (2), a constant head supply tank (3), a swirler (4), tube test section (5), holder of orifices (6), piezometer (7), a vane moving measure (8), support bar (9) and a dye injection system (10). More details about the swirler and orifice holder are shown in Fig. 1 (b) \& 1 (c), respectively.

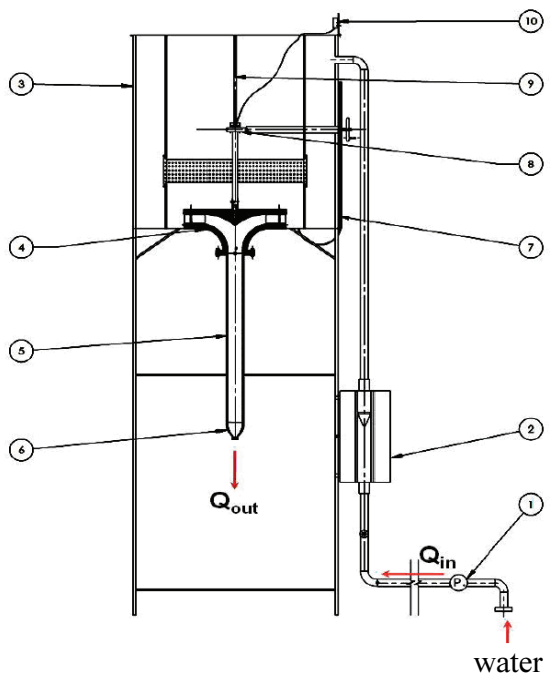

1-Feed water

pump

2- Rotameter

3- Constant

head supply

tank

4- Swirler.

5- Test section

tube.

6-Holder of

orifices.

7-Piezometer.

8-Vane moving

system

9- Support bar.

10- Dye

injection

system

Fig. 1 (a). Test rig layout. 


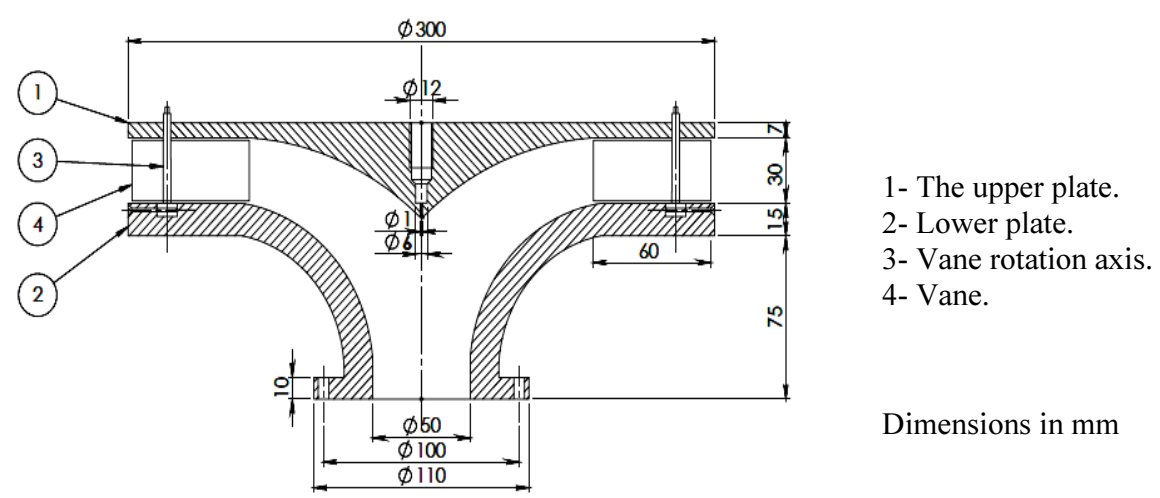

Fig. 1(b). The Upper and lower plates of the swirler.

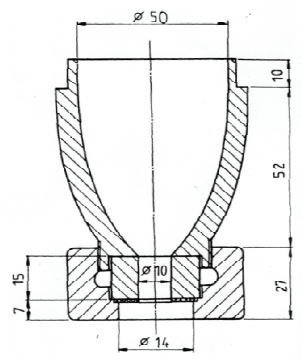

Dimensions in $\mathrm{mm}$

Fig. 1(c). The orifice holder.

The constant head supply tank is composed of two coaxial square cross section tanks. The outer tank is constructed from four sides made of galvanized sheet $0.2 \mathrm{~cm}$ thickness, have dimensions of $75 \mathrm{~cm} \times 75 \mathrm{~cm} \times$ $100 \mathrm{~cm}$ and a part of its base was made of a plexiglas (prespex), $58 \mathrm{~cm} \times$ $58 \mathrm{~cm}$, to facilitate visualization of the vane angle setting. The inner tank is also made of galvanized steel sheet with dimensions of $48 \mathrm{~cm} \times 48 \mathrm{~cm}$ $\times 100 \mathrm{~cm}$ and located coaxially with the outer tank. The four sides of the inner tank have 400 holes, of $0.15 \mathrm{~cm}$ diameter, located on a height of 20 $\mathrm{cm}$ from lower end. These holes are distributed in three rows and are covered by a very narrow plastic mesh in order to have a calm flow at the swirler entrance.

To supply the flow with the amount and direction of swirl, a special swirler with movable vanes was designed and manufactured. The swirler is constructed from two circular streamlined plates; the upper plate was a streamlined conic solid prespex piece (center body) having a diameter of 
$30 \mathrm{~cm}$ at its base. This piece has two functions. First, it was part at the entrance channel which conveyed the fluid to the tube test section. Second, it contained one central hole with diameter $0.1 \mathrm{~cm}$ for the injecting the dye into the flow field. Between the upper and the lower plates thirty guide vanes were located, each vane was made of perspex as aerofoil NASA 0012 with dimensions $6 \mathrm{~cm}$ chord and $3 \mathrm{~cm}$ span. These vanes were placed symmetrically in a circular array around the center body at a radius of $13 \mathrm{~cm}$. Since the amount of swirl imparted on the fluid is affected by the vane angle setting, $\Phi$, so it was necessary to design a precise system for the movement and changing the vane angles.

To determine the downstream effect on the vortex breakdown phenomena, two tubes of lengths $60 \& 120 \mathrm{~cm}$ were used. The two tubes have constant inner diameter of $5 \mathrm{~cm}$. The tube was mounted vertically and fixed with the lower plate of the swirler through two flanges. The lower end of the tube was equipped with an orifice holder. The set of 15 orifices were used; orifice bore diameter ranged from $0.3 \mathrm{~cm}$ to $1 \mathrm{~cm}$, in order to make the corresponding Reynolds numbers ranged from 662 to 9935 for short tube and from 872 to 10737 for long tube. A scale was sticked on the outer surface of the tube to measure breakdown position.

The phenomenon was visualized by injecting dye, known as mepthilin blue, through dye injection device. The injection plastic tube was connected to $0.1 \mathrm{~cm}$ diameter central hole to introduce the dye filament on the centerline of the test section. The dye reservoir was placed at a suitable adjustable elevation.

The present research has concentrated on studying the effect of varying Reynolds and circulation numbers on the vortex breakdown position as well as on the swirl angle distribution in a zone ahead of breakdown. The circulation number, $\Omega$, was varied by changing the vane angle setting through a swirler for clockwise and anti-clockwise flow directions, see Fig. 2, while the Reynolds number was changed by controlled inlet valve opening and by using a group of orifices which were fitted at the downstream end of the tube test section. The values of the dimensionless orifice bore diameter $(\mathrm{r} / \mathrm{R})$ based on the tube inner radius, $\mathrm{R}$, and the corresponding Reynolds number, Re, are found in ElSyed $^{[29]}$. The parameters that could be systematically varied and monitored were the volume flow rate and vane angle. These parameters 
are described by the dimensionless parameters; Reynolds number, Re, and circulation number, $\Omega$.

The Reynolds number $(\mathrm{Re})$ used is defined as $\mathrm{Re}=4 \mathrm{Q} / \pi \mathrm{D} v$, where $\mathrm{Q}$ is the volume flow rate, $\mathrm{D}$ is the tube inner diameter and $v$ is the kinematic viscosity of the water. The circulation number, $\Omega$, is the circulation normalized based on the average axial velocity $\mathrm{w}$ multiplied by the tube diameter D. However, $\Omega=\tilde{\Gamma} \mathrm{w} \mathrm{D}$, where $\Gamma$ is the circulation at the trailing edge of the swirl vane. It is equal $\Gamma=2 \pi \mathrm{R}_{\mathrm{x}} \mathrm{v}$, where, $\mathrm{R}_{\mathrm{x}}$ is the radial distance from the tube center to the trailing edge of the vane and $\mathrm{v}$ is the swirl velocity component of the flow leaving the vane. More details about the calculation of Re $\& \Omega$ are explained in El-Syed ${ }^{[29]}$.

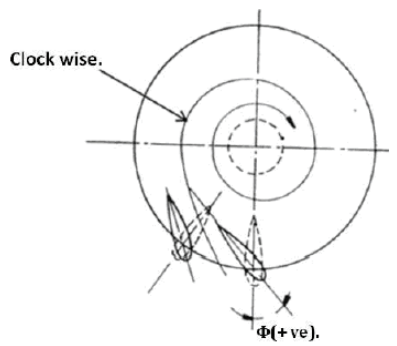

$\mathrm{a}-$ Clockwise flow direction.

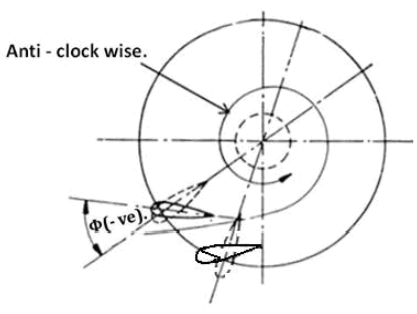

$\mathrm{b}-$ Anti-clockwise flow direction.

Fig. 2. The two vanes angle setting viewer from top.

\section{Experimental Results and Discussion}

In the present work six modes were observed, four of these modes are classified as wide spiral (type 1), double helix (type 2), flattened bubble (type 3), and fragments spiral (type 4). The other two modes are the so-called bubble "axis-symmetric" and "spiral" vortex breakdown. These modes were photographed by a camera Canon model EOS 1000D with 10.1 Mega-pixels resolution, 2.5 inch LCD display, up to 3 frame per second and 5xoptical zoom.

The experimental study was conducted for two tubes one $60 \mathrm{~cm}$ long $(\mathrm{L} / \mathrm{R}=24)$ and the other $120 \mathrm{~cm}$ long $(\mathrm{L} / \mathrm{R}=48)$. The set of experiments was performed under constant Reynolds number, Re, while the circulation number, $\Omega$, was increased. The vanes angles range covered in the experiments was from $28^{\circ}$ to $47^{\circ}$ whereas the corresponding circulation range from 1.073 to 2.48, respectively. For each vane angle setting the flow pattern was observed and the type as 
well as the axial position of the flow disturbance were recorded. It should be noted that each observation required between fifteen to twenty minutes for the disruption to achieve steady state condition. The modes showed a fixed order of succession as the Reynolds number was kept constant and the circulation number was increased by suitable increments.

\subsection{Vortex Breakdown Modes}

The classification and the description of the above mentioned modes will be debated as follows:

\subsubsection{Type 1 - Wide spiral mode}

The central dye filament traveled along the tube test section axis with no deflection when the vanes directed radially $\Phi=0$. As the swirl was imparted gradually to the fluid the central dye filament shows a slight oscillation in the filament near the downstream end of the tube test section. As the swirl was increased further the central filament moved gently, but distinctly, off axis at a nearly constant azimuthal location. Only after it had moved off the axis a significant filament seem to acquire the spiralling sense of the base flow.

According to the observations obtained during the experiments, it appears that at Reynolds number, Re, range from 662 to 2615 for $\mathrm{L} / \mathrm{R}=24$ and $\mathrm{Re}$ range from 872 to 1946 for $\mathrm{L} / \mathrm{R}=48$ a wide spiral mode (type 1 ) is dominated. Plates ( $1 \mathrm{a} \&$ b) show sample typical observation of type 1 mode at $\Omega=1.286$ with $\mathrm{Re}=1946$ for $\mathrm{L} / \mathrm{R}=48$ and with $\mathrm{Re}=2615$ for $\mathrm{L} / \mathrm{R}=24$, respectively.

\subsubsection{Type 2 -Double helix mode}

In type 2 mode the sheared filament (tape form ) began to expand into a slightly curved triangular sheet, each half of this sheet wrapped around the other into the form of the double helix (type 2 in our classification). Plate (2) shows the double helix modes at $\mathrm{Re}=1520$ with $\Omega=1.996 \& \mathrm{~L} / \mathrm{R}=48$. It should be noted that both of type (1) mode and type (2) mode appeared alternatively under the same flow conditions. The above observations were valid except for values of $\mathrm{Re}=1946,2535$ $\&$ 2615; where the type 3 (flattened bubble) is developed directly from type 1 mode. It is noted that, after considerable time, the newly emerged branch often becomes predominant, the original branch disappeared, and 
the type 1 form resulted. This type of the double helix is found to be highly sensitive to any small disturbance.

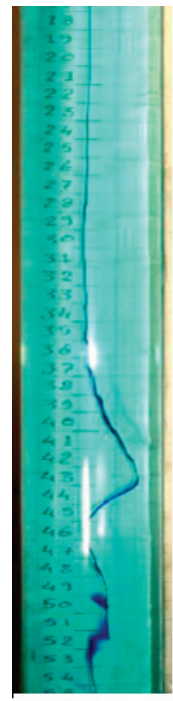

(a)

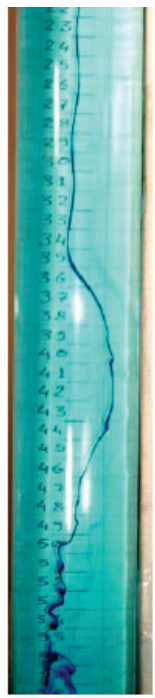

(b)

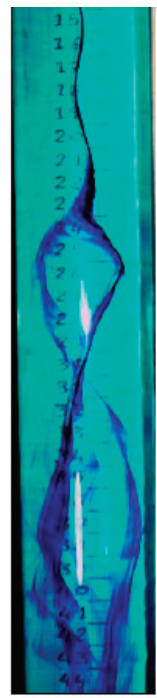

PL. (1) Type 1 disturbance mode. PL. (2) The double helix mode.

(a) For $(\operatorname{Re}=1946$, $\Omega=1.286 \& L / R=48)$

$$
\operatorname{Re}=1520, \Omega=1.996 \& L / R=48)
$$

(b) For $(\operatorname{Re}=2615$, $\Omega=1.286 \& L / R=24)$

\subsubsection{Type 3 -Flattened bubble mode}

The flattened bubble mode of flow disturbance occasionally evolved directly form type 1. This transformation either occurred spontaneously, at fixed flow condition, or could be induced by slight increase of the swirl. In both cases, the sheared deflected filament of type (1) disturbance abruptly began to roll up, back toward the initial point of deflection, into a tight spiral. As this occurred, the filament downstream totally disappeared, including that all the dye reaching the disturbance has been recirculated, PL. (3). After few seconds the dye began to exit from this recirculation zone and travel downstream, and the flattened bubble disturbance was fully formed. Usually, the dye leaves the recirculation zone in a fairly random fashion, occasionally; several distinct emptying paths were formed, as shown in PL. (4 a\&b). 


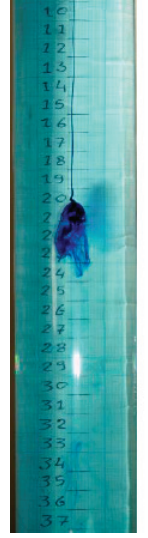

PL. (3) The birth of the flattened bubble mode. $(\operatorname{Re}=$ $2615, \Omega=1.6 \& L / R=24)$.

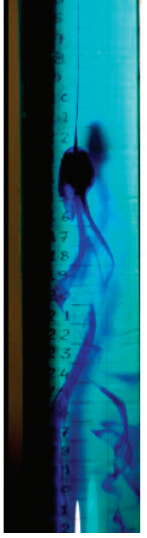

(a)

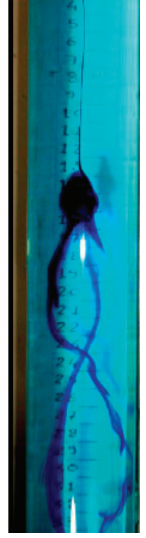

(b)
PLs. (4 a \& b) A flattened bubble mode with several distinct empting $(\operatorname{Re}=1520, \Omega=2.275 \& \mathrm{~L} / \mathrm{R}=48)$.

\subsubsection{Type 4 -Fragments spiral mode}

This type of flow disturbance has some characteristics similar to those of the flattened bubble and spiral modes. Although the transition from the flattened bubble to type (4) and also from type (4) to the spiral form were gradual. The transition condition can not be defined precisely. This is mainly attributed to the random cyclic behavior of the rapidly decelerated and abruptly moving a fragments flow off axis to form a sharp kink. Similar to the spiral form, and make a fragments of dye which is previously broken off a distinct filament downstream of the initial disturbance, as seen in PL. (5) for $\mathrm{Re}=1520, \Omega=2.275$ $\& \mathrm{~L} / \mathrm{R}=48$. Also in this type, the filament appeared to simultaneously shear slightly and some of the dye spread laterally to mark the envelope of the remnants of the flattened bubble.

\subsubsection{Spiral mode}

In this mode of flow disturbance, the dye filament marking the swirl axis decelerated rapidly and formed an abrupt kink. The filament did not spread out appreciably, but instead took the form of a spiral which persisted for one or two turns before breaking up into large scale turbulence as show in PL. (6) for $\mathrm{Re}=3548$ and $\Omega=1.6$ with $\mathrm{L} / \mathrm{R}=24$. The same observation can be noted for $\mathrm{L} / \mathrm{R}=48$ with $\mathrm{Re}=4071$ and $\Omega=1.831$ as shown in PL. (7). In addition, the whole spiral configuration rotated in a periodic fashion about the tube axis and the frequency of this rotation was increased as the Reynolds number or circulation number increased. 


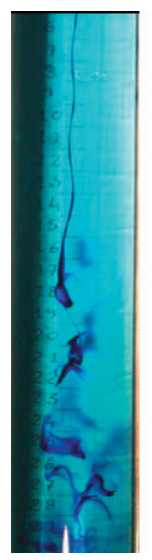

PL. (5) A type 4 disturbance. Fragments of dye filament.

$(\operatorname{Re}=1520, \Omega=2.275 \& L / R=48)$.
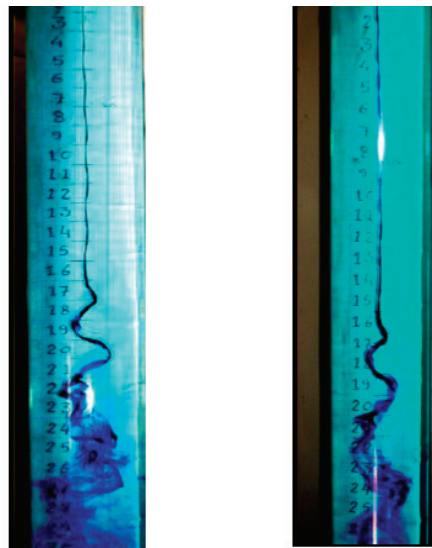

PL. (6) The spiral mode $(\operatorname{Re}=3548, \Omega=1.6 \&$ $\mathbf{L} / \mathbf{R}=\mathbf{2 4})$.
PL. (7) The spiral mode. $(\operatorname{Re}=4071, \Omega=1.831 \&$

$\mathbf{L} / \mathbf{R}=\mathbf{4 8})$.

\subsection{Bubble mode}

This mode is known as the axisymmetric mode of vortex breakdown. The bubble form is characterized by stagnation point on the swirl axis, followed by an abrupt expansion of the centerline dye filament to form the envelope of a bubble of the recirculating fluid. The envelope has high degree of the axisymmetric over most of its length, but the rear is not closed and is asymmetric as shown in PL. (8). After a distance of approximately one bubble length, the new core deflected, following an abrupt kink, into a loose spiral configuration. This spiral seldom formed another bubble, which is possibly due to the instabilities, and after a few turns broke into large scale turbulence.

In fact, the bubble was observed to fill and empty in two different ways. In the first way, as shown in PL. ( 9 a) for $\operatorname{Re}=1787$ and $\Omega=2.48$, the bubble was filled and emptied at diametrically opposite locations near the rear bubble end, that is mean at any instant the bubble was being filled at one azimuthal location and was being emptied at another azimuthal location, 180 degree away form the first. The downstream end of the breakdown was tilted, and the filling took place at that point farthest upstream and the emptying occurred near the farthest downstream point. The emptying tail of the breakdown tended to return to the tube axis, PL. $(9 \mathrm{~b})$ for $\mathrm{Re}=3312 \& \Omega=1.996$. This case of filling and emptying was the most commonly observed one. 
The second way is shown in PL. ( 9 c), for $\operatorname{Re}=2535 \& \Omega=$ 2.275 , which was rarely observed, when the bubble has the temporary an appearance of a filament took of dye on the axis inside it. The filament took the form of a screw worm and extended from just downstream of the nose of bubble to the downstream end of the bubble before being broken up. This filament was fed by a reservoir of dye located near the nose of the bubble. The screw worm filament would then appear and persist until the reservoir was exhausted. This occurred randomly in time. This type of bubble was observed by Bellamy Knights ${ }^{[20]}$ and also noticed by Faler and Leibovich ${ }^{[5]}$ and Bayomi ${ }^{[22]}$. Bellamy Knights reported that worm is extended until the lower of bubble while Faler and Leibovich showed that the worm only extended to two thirds of the bubble length. Both spiral and bubble vortex breakdown show high degree of structural stability, except for flow settings permitting spontaneous transformations between types. In this case, the first turn of the spiral, PL. (10 a), would fold back toward the initial kink on the tube axis, and the spiral change into bubble mode as shown in PL. (10 b). The resultant bubble, usually with the rear portion not fully developed, then moved quite rapidly upstream. The newly formed bubble would persist only a few seconds and then changed abruptly, back to a spiral mode which immediately moved downstream to its original location.

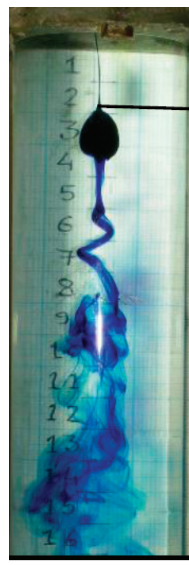

PL. (8) The axisymmetric vortex breakdown mode

$(\operatorname{Re}=\mathbf{2 6 1 5}, \Omega=$ 2.275, $\mathrm{L} / \mathrm{R}=\mathbf{2 4}$ ).

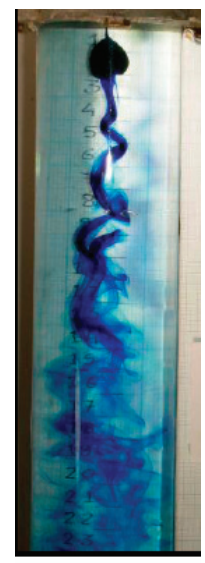

PL. (9 a) The wake instability for filling $\&$ emptying of the bubble. $(\operatorname{Re}=1787$, $\Omega=2.48 \& \mathrm{~L} / \mathrm{R}=$ 24)

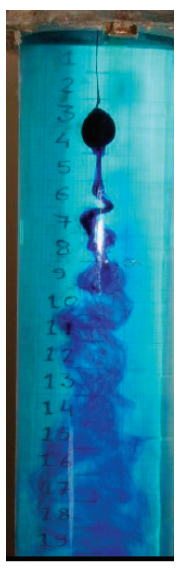

PL. (9 b) The emptying tail of the breakdown tended to return to the tube axis. $(\operatorname{Re}=3312, \Omega=$ $1.996 \& L / R=24)$.

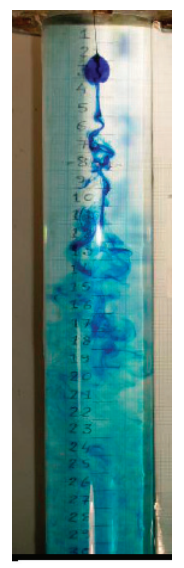

PL. (9 c) The spiralling of the vortex core in the bubble. $(\operatorname{Re}=$ 2535, $\Omega=2.275 \&$ $\mathbf{L} / \mathbf{R}=\mathbf{2 4 )}$. 


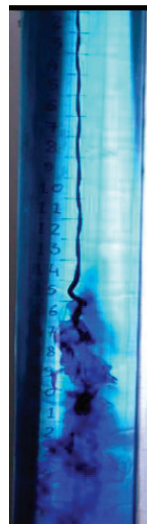

(a)

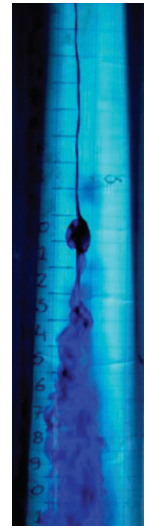

(b)

PL. (10) An example of the transition from bubble to spiral disturbance in the hysteresis zone $(\operatorname{Re}=4870, \Omega=1.6 \& L / R=24)$.

\subsection{Vortex Breakdown Position Results}

The vortex breakdown position is the distance from the tube entrance to the point at which the vortex is bursting. This bursting was showed to move upstream and downstream in an unpredictable way with no noticeable change in the external conditions. This tendency of moving is due to the instability, Harvey ${ }^{[19]}$. The vortex breakdown position is regarded as the arithmetic average value of the minimum and the maximum movement of the vortex breakdown. As mentioned before the present experiments were carried out with the two swirl flow directions, and applied on the two tubes with dimensionless, $\mathrm{L} / \mathrm{R}=24$ and $\mathrm{L} / \mathrm{R}=48$.

The circulation numbers for both tubes cases were ranged from 1.073 to 2.48 in the clockwise flow direction and from 1.073 to 1.831 in the anti-clockwise flow direction. The Reynolds number was varied in both directions from 662 to 9935 for $\mathrm{L} / \mathrm{R}=24$ and from 872 to 10737 for $\mathrm{L} / \mathrm{R}=48$.

\subsubsection{Results of breakdown position with $L / R=24$}

The results of the dimensionless breakdown position normalized by tube radius, $Z^{+}=Z / R$, for tube $L / R=24$ are plotted against $R e$ for nine different values of $\Omega$ at clockwise flow direction in Fig. (3). It can be seen from this figure that, the type and the disturbance location are dependent on both the Re and $\Omega$. For fixed flow rate the disturbance mode is moved upstream as the imparted swirl was increased. 
For fixed circulation number $(\Omega)$ the disturbance was also moved upstream as Reynolds number (Re) was increased. For example from Fig. 3, at $\Omega=1.6$ and $\mathrm{Re}=1241$ the disturbance was found to be wide spiral (type 1) at a distance about $\mathrm{Z}^{+}=10.5$, point (a). When Reynolds number is increased to 1787 the type (1) is still being occurred but the disturbance moved upward to a new position of $Z^{+}=9.6$ point (b). As $R e$ increased to 2535 the mode shape was changed from type (1) to type (2) and then moved upstream to a new position $\mathrm{Z}^{+}=9.2$, point (c). More increase in Reynolds number to 2615, the type (2) change to type (3) and it is moved upward to axial position $\mathrm{Z}^{+}=8$ point (d). At fixed flow condition this flattened bubble is then moved upstream and changed to fragment spiral form (type 4) at $\mathrm{Z}^{+}=7.8$ point (e). As Reynolds number was increased to 3548 the type (4) is moved upward to $Z^{+}=6.8$. With a slight increase of Reynolds number to 4006 the type (4) was changed to spiral mode, and moved upward position $\mathrm{Z}^{+}=5.4$ point $(\mathrm{g})$. More increase in $\operatorname{Re}$ to $\operatorname{Re}=5886$ the spiral and bubble modes happened with mean axial location $\mathrm{Z}^{+}=3.2$ points $(\mathrm{h}, \mathrm{i})$. At this flow condition this bubble is then moved downstream and changed to spiral form. As Re was increased to 7206 the bubble with closed downstream end mode is only detected at $\mathrm{Z}^{+}=2.8$, point (j). For further increase to Re from 7762 to 9935 , the bubble with open downstream end found to be dominated and moved upward from $\mathrm{Z}^{+}=2.3$ to 1 , points $(\mathrm{k}, 1 \& \mathrm{~m})$.

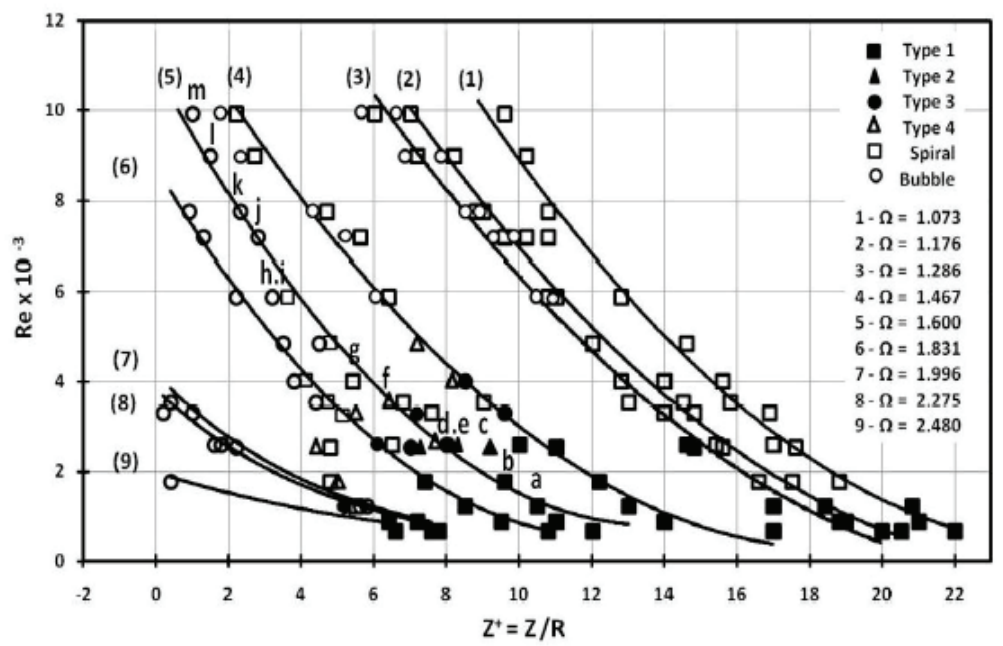

Fig. 3. Vortex breakdown position as function of Reynolds number and circulation number (at clockwise flow direction for $L / R=24$ ). 
Figure 4 shows the relationship between Re and the breakdown position for different circulation number for anti-clockwise direction. From the figure same procedure was followed as in the clockwise direction. It is clear that if some one draw a line representing a constant Reynolds number for example see Fig. 4, the dashed line shows a constant Re of 1787 and circulation number changed from 1.073 to 1.831 . The wide spiral was observed to be occurred and moved upstream from $\mathrm{Z}^{+}=12.8$ at $\Omega=1.073$ to $\mathrm{Z}^{+}=8$ at $\Omega=$ 1.286 , see PLs. (11 A, B \& C). For $\Omega$ equal to 1.467 type (1) is changed to type (3) but the dye exit with two branches rolled as the double helix mode as shown in PL. (11 D). As the circulation number increased to $\Omega=1.831$ the bubble form was observed and moved upstream from $\mathrm{Z}^{+}=1.6$ to $\mathrm{Z}^{+}=0.2$ as shown in PLs. (11 E \& 11 F). From Fig. (3 \& 4), it is clear that, the type of the disturbance mode and its location breakdown position were depended on the Reynolds and the circulation number and also on the sense of swirl rotation (clockwise and anti-clockwise).

It can be noted from Fig. $3 \& 4$ that, the breakdown position for vanes were set in anti-clockwise direction are always upstream of the breakdown position when the vanes were set in clockwise direction. This is may be, the effect of Coriolis force which add some circulation to the anti-clockwise flow direction.

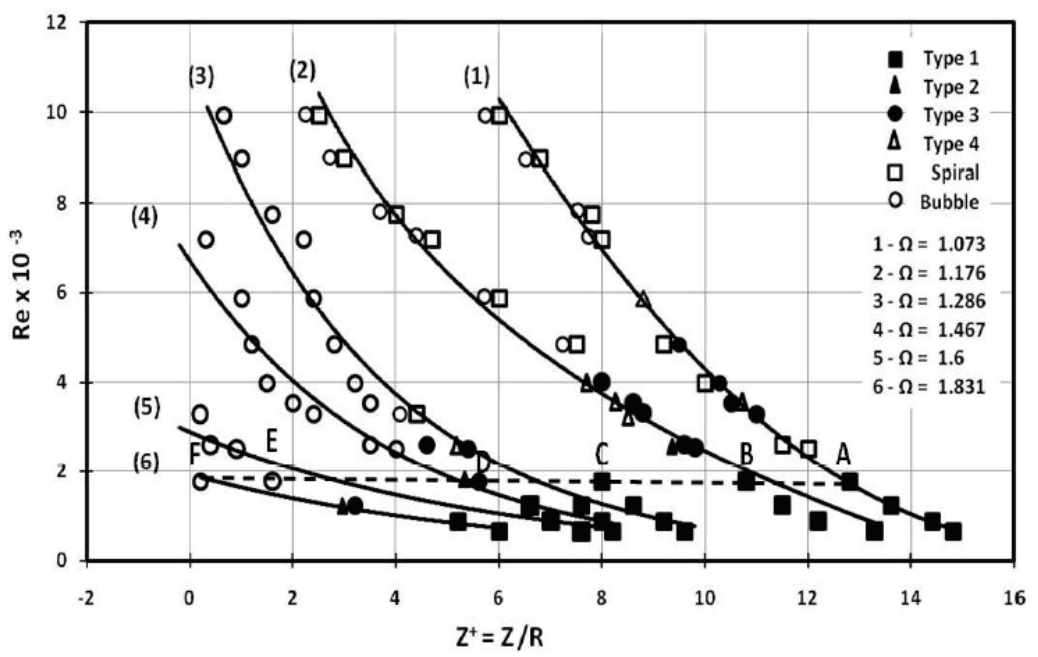

Fig. 4. Vortex breakdown position as function of Reynolds number and circulation number (at anti-clockwise flow direction for $L / R=24$ ). 


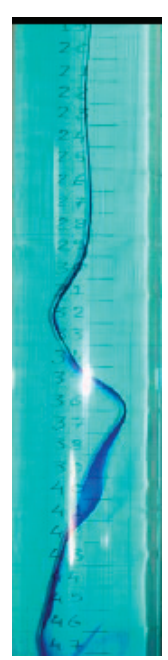

(A)

$\mathbf{\Omega}=\mathbf{1 . 0 7 3}$

$Z^{+}=12.8$

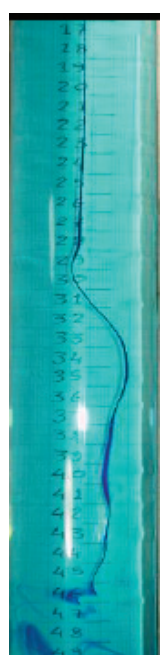

(B)

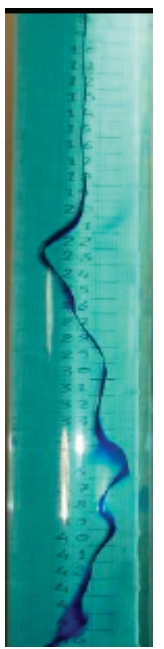

(C)

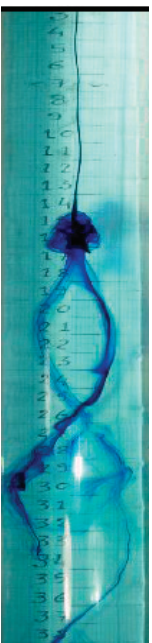

(D)

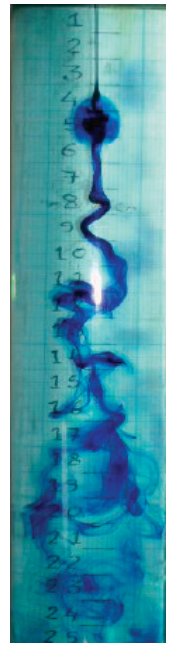

(E)

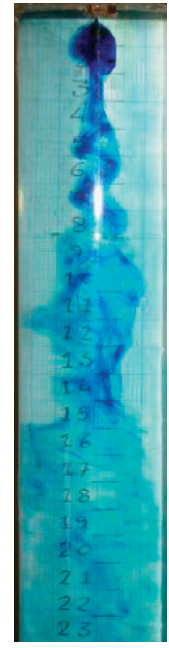

(F)

$$
\begin{array}{lll}
\Omega=\mathbf{1 . 4 6 7} & \mathbf{\Omega}=\mathbf{1 . 6} & \mathbf{\Omega}=\mathbf{1 . 8 3 1} \\
Z^{+}=\mathbf{5 . 6} & \mathrm{Z}^{+}=\mathbf{1 . 6} & Z^{+}=\mathbf{0 . 2}
\end{array}
$$

PL. (11) (A - F) Sample of the different modes of the vortex breakdown position for fixed

$R e=1787$ and different circulation number, in anti-clockwise flow direction.

\subsubsection{Results of breakdown position with $L / R=48$}

The results of breakdown position are plotted against Reynolds number $(\mathrm{Re})$ with different values of circulation number $(\Omega)$ for both flow directions (clockwise and anti-clockwise), in Fig. $5 \& 6$. For circulation number equal to 1.831 and Reynolds number is increased from 872 to 6888 , the symbols A, B, C, D and E are written on this curve in Fig. 5 to show how the modes of the disturbances are occurred and changed. From Fig. 5 it can be noted that, the wide spiral mode was observed to be moved upstream from point $\mathrm{A}$ with $\mathrm{Re}=872$ at $\mathrm{Z}^{+}=10.8$ to point $\mathrm{B}$ with $\mathrm{Re}=1520$ and $\mathrm{Z}^{+}=10$. With further increase to $\mathrm{Re}=$ 2990 type (1) was changed directly to type (3) with axial position equal to $Z^{+}=7.4$, while at point $C$ type (4) changed to spiral mode when $\mathrm{Re}$ equal to 4071 and moved up to $Z^{+}=5.6$. Finally the Reynolds number changed from 4655 to 6888 the mode type becomes the bubble mode and it moved upstream from 3 to 0.8 at point $\mathrm{D}$ and $\mathrm{E}$.

Figure 6 shows the relationship between Re and the breakdown position for anti-clockwise flow direction. From the figure, the clockwise observed modes were also detected, but at different values of circulation number and Reynolds number. For $\Omega=1.6$ type 1 was found at $\operatorname{Re}=$ 
1242 and directly changed to bubble at $\mathrm{Re}=1520$ with breakdown position changed from $\mathrm{Z}^{+}=6.4$ to $\mathrm{Z}^{+}=2.2$. The bubble is moved upstream to the entrance and the tube test section is full by mixing turbulent region at $\mathrm{Re}=4071$.

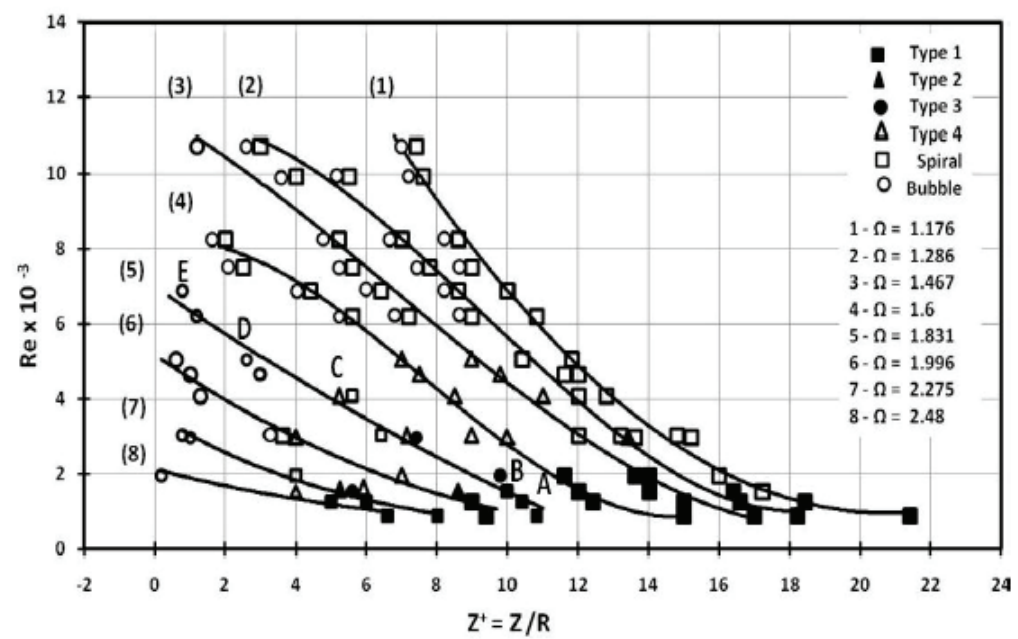

Fig. 5. Vortex breakdown position as function of Reynolds number and circulation number (at clockwise flow direction for $L / R=48$ ).

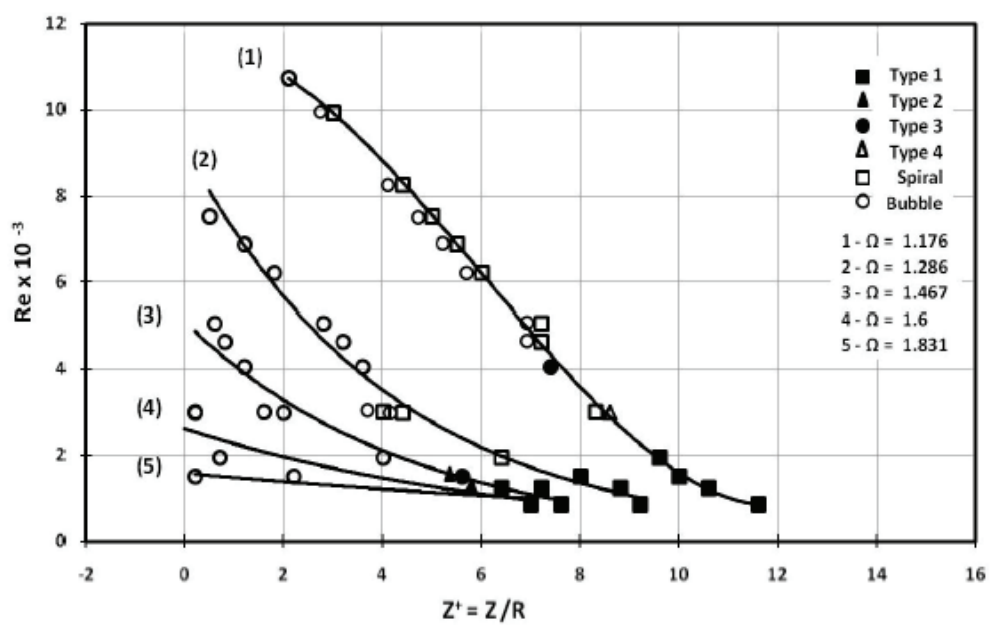

Fig. 6. Vortex breakdown position as function of Reynolds number and circulation number (at anti-clockwise flow direction for $L / R=48$ ). 
The comparison between clockwise and anti-clockwise flow direction cleared that the breakdown position for vanes were set anticlockwise flow direction are always upstream of the breakdown position when the vanes were set to the clockwise flow direction.

\subsubsection{Effect of pipe length}

The comparison between the results, which obtained from clockwise and anti-clock wise flow direction for the two tubes cleared that at circulation number equal to 1.176 the breakdown positions for the long and short tubes are approximately the same when vanes set at clockwise flow direction. As the circulation number increased to 1.286 the breakdown position moved upstream for long tube compared with short tube. More increase of circulation to / or over 1.467 the breakdown position moved upstream for short tube compared with long tube.

Comparison between the result of breakdown position for long and short tube when vanes set at anti-clockwise flow direction cleared that for small $\Omega=1.176$ approximately the breakdown position are the same for long and short tube. As the $\Omega$ increased to 1.286 or more the breakdown position is moved upstream for long tube compared with short tube.

\section{Conclusion}

A number of interesting conclusions can be drawn from the results of the present experimental investigation on the swirled flow through a vertical circular straight tube:

1) The results revealed that there is a total of six distinct modes of the disruption of the vortex core as Re and $\Omega$ of the flow were varied. Four of these modes type 1 (wide spiral), type 2 (double helix), type 3 (flattened bubble) and type 4 (fragment spiral) occurred at Reynolds number from 662 to 3312 for $\mathrm{L} / \mathrm{R}=24$ and Reynolds number ranged from 872 to 5069 for $\mathrm{L} / \mathrm{R}=48$. The other modes occurred at the highest values of $\mathrm{Re}$ and defined by spiral and bubble (axis-symmetric) mode depends upon circulation, $\Omega$. The spiral and the bubble mode occasionally occurred at the flow condition in the hysteresis zone and the bubble mode become dominant and shrinked in size (both diameter and length) as the Re or $\Omega$ was increased. Type 2 and type 3 occurred from type 1 by slight increase of the swirl. Type 4 has some characteristics of those of type 3 and the spiral mode. 
2) The breakdown position was found to be dependent on both Re and $\Omega$ of the flow. Whereas, for all Re values an increase in $\Omega$ always results in moving the breakdown position upstream. A considerable increase in $\Omega$ leads to a transformation to another type of the disruption modes. An upstream movement of the breakdown also resulted, in general, when $\operatorname{Re}$ is increased of a constant value circulation number $\Omega$.

3) The breakdown position values are smaller for anti-clockwise flow direction than that, when vanes were set clockwise flow direction for long tube $(\mathrm{L} / \mathrm{R}=48)$ and short tube $(\mathrm{L} / \mathrm{R}=24)$.

4) In case of circulation number equal to 1.176 a small influence of the breakdown position values can be noted for long and short tube with clockwise and anti-clockwise flow direction.

5) In case of clockwise flow direction the breakdown position occur downstream in the short tube than that in long tube at circulation number $\Omega=1.286$, but when circulation number increased up to 1.467 the breakdown position occurs early in the short tube than that in the long tube. With more circulation number, there is no effect on the breakdown position can be detected.

6) In case of anti-clockwise flow direction the breakdown position always happened downstream in the short tube than that in the long tube for all circulation numbers except when circulation number equal or greater than 1176 , a very small effect on the breakdown position can be noticed.

\section{References}

[1] Hall, M.G., "Vortex breakdown", Annual Review of Fluid Mechanics, 4: 195 - 218, (1972).

[2] Leibovich, S., "The structure of vortex breakdown ", Annual Review of Fluid Mechanics, 10: 221 - 246, (1978).

[3] Sarpkaya, T., "On stationary and travelling vortex breakdown", Journal Fluid Mechanics, 45: $545-559,(1971)$.

[4] Sarpkaya, T., " Turbulent vortex breakdown ", Journal Physics Fluid, 7: 2301-2303, 1995.

[5] Faler, J.H. and Leibovich, S., "Disrupted states of vortex flow and vortex breakdown", Journal Physics Fluid, 20: 1385 - 1400, (1977).

[6] Garg, A.K. and Leibovich, S., "Spectral characteristics of vortex breakdown flowfield", Journal Physics Fluid, 22: 2053 - 2064, (1979).

[7] Leibovich, S., "Vortex stability and breakdown: survey and extension", AIAA Journal, 22: $1192-1206,(1984)$.

[8] Lucca-Negro, O. and O'Doherty, T., "Vortex breakdown: a review", Proceeding Energy Combustion Science, 27: 431 - 481, (2001).

[9] Peckham, D.H. and Atkinsion, S.A., "Preliminary Results of Low Speed Wind tunnel Tests on a Gothic Wing of Aspect Ratio", 1.0. ARC technical report, CP No. 50, (1957).

[10] Srigrarom, S. and Ridzwan, M., "An experimental investigation of perturbations on vortex breakdown over delta wings," $16^{\text {th }}$ Australasian Fluid Mechanics Conference, Crown Plaza, Gold Coast, Australia, 2-7 December (2007). 
[11] Srigrarom, S. and Lewpiriyawong, N., "Controlled vortex breakdown on modified", Journal of Visualization, 10, No. 3: 299-307, (2007).

[12] Sharma, C.L., Soundranayagam, Somkrishan, S. and Mukund, T.S., "Dependence of vortex breakdown on angular momentum parameter in draft tube flows", Current Science, 75, No. 12: 1355-1363, December (1998).

[13] Cervants, M.J., "Counter rotating runner cone in a Kaplan elbow draft tube for increased efficiency", $3^{\text {rd }}$ IAHR International Meeting of the Worksgroup on Cavitation and Dynamic Problems in Hydraulic Machinery and Systems, October 14-16- (2009), Brno, Czech Republic.

[14] Stein, O. and Kempf, A., "LES of the Sydney swirl flame series: A steady of vortex breakdown in isothermal and reacting flows", Proceedings of the Combustion Ins., 31: 1755-1763, (2007).

[15] Tangermann, E and Pfitzner, M, "Evaluation of combustion models for combustioninduced vortex breakdown", Journal of Turbulence, January (2009).

[16] Aksel, M.H. and Kaya, M.T., "A numerical simulation of the axisymmetric vortex breakdown in a tube", Applied Mathematical Modeling, 16, Issue 8: 414-422 (1992).

[17] Jochmann, P., Sinigersky, A. and Hehel, M., "Numerical simulation of a processing vortex breakdown", International Journal of Heat and Fluid Flow, 27: 192 - 203 (2006).

[18] Harvey, J.K., "Analysis of the Vortex Breakdown Phenomenon", Imperial College, Department of aeronautics, Report No. 103, (1960).

[19] Harvey, J.K., "Some observation of the vortex breakdown phenomenon", Journal Fluid Mechanics, 14: 585 - 592, (1962).

[20] Bellamy - Knights, P.G., "A note on vortex breakdown in a cylinder tube", Journal Fluid Engineering, 98: 322 - 323, (1976).

[21] Faler, J.H. and Leibovich, S., "An experimental map of the internal structural of a vortex breakdown", Journal Fluid Mechanics, 86: 313 - 335, (1978).

[22] Bayomi, N.N., "An investigation of vortex breakdown phenomena in a tube", M.Sc., Faculty of Engineering, Mataria, Helwan University, (1990).

[23] Heikal, H.A., Said, M.H. and Bayomi, N.N., "Investigation of vortex breakdown phenomena", $7^{\text {th }}$ Proceedings of International Conference for Mechanical Power., Cairo University, 17 - 29 December (1990).

[24] Althaus, W., Krause, E., Hofhous, J. and Weimer, M., "Bubble and spiral type breakdown of slender", Experimental Thermal and Fluid Science, 11: 276 - 284, (1995).

[25] Hourigan, K., Graham, L.J.W. and Thompson, M. C., "Spiral streaklines in pre-vortex breakdown regions of axisymmetric swirling flows", Physics Fluid, 7 (12): 3126-3128, December (1995).

[26] Bhattacharyya, S. and Pal, A., "Axisymmetric vortex breakdown in a filled cylinder", Journal Engineering Science, 36, NO. 5/6: 555 - 563, (1998).

[27] Husain, H. S., Shtern, V. and Hussain, F., "Control of vortex breakdown by addition of near-axis swirl", Physics of Fluids, 15, (2) February (2003).

[28] Said, M.H., "Experimental and numerical simulation of vortex breakdown modes in a tube", Engineering Research, Journal, Helwan University, 104: M18 - M38, April (2006).

[29] El - Syed, Abd EI - Nabi Zaghloul, "An experimental investigation on vortex breakdown in a vertical tube", M.Sc., Faculty of Engineering, Mataria, Helwan University, (2009). 


\section{بحث تجريبي عن انقطاع الدردورة في أنبوبة أسطو انية رأسية}

نزيه نعمان بيومي، و محمد حسين سعيد ، و ممتاز فهمي سدر (ك **"،

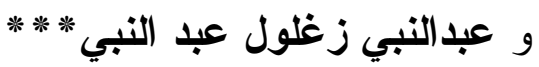

جامعة الملك عبد العزيز-جدة- المدلكة العربية السعودية،

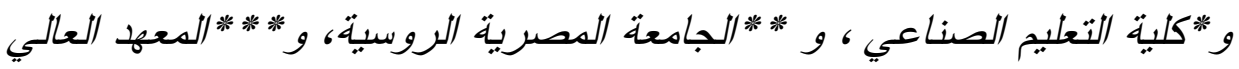
للهنسة - أكاديمية الثروق - القاهرة - جهورية مصر العربية

الدستخلص. يتعرض التذفق الدوامي إلى عدد من التغيرات الرئيسية

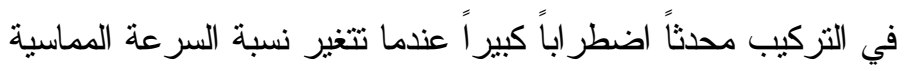

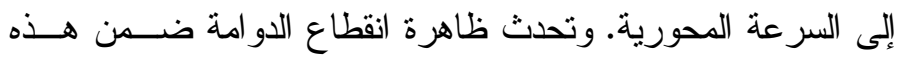
التغيرات التزكيبية. وتعثبر هذه الظاهرة إحدى مشاكل عدم الاستقرار

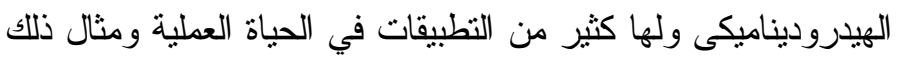

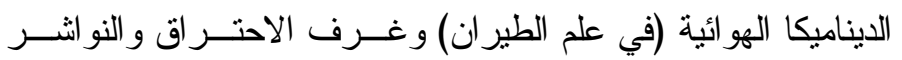

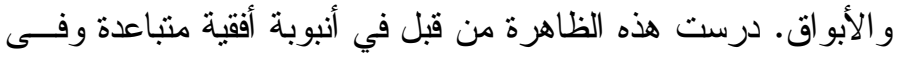

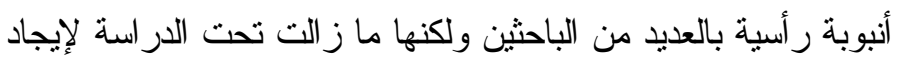
تفاصيل أكثر عن هذه الظاهرة.

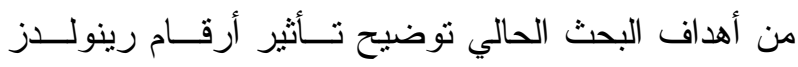
و التدويم على الأثكال المختلفة للاردورة و وأوضاعها وذللك باستخدام

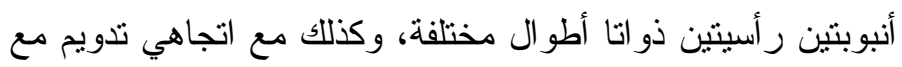
عقارب الساعة وعكس عقارب الساعة.

أوضحت النتائج وجود ستة أثنكال لظاهرة انقطاع الدردورة

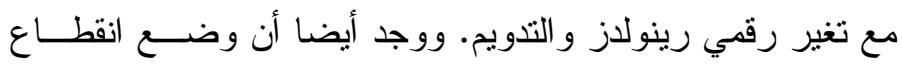

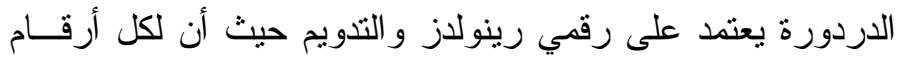


رينولدز عند ازدياد رقم التدويم تتحرك الــدردورة إلــى أعلــي.

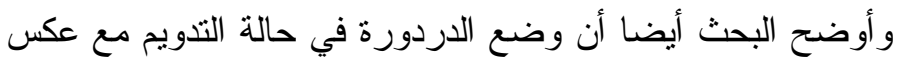

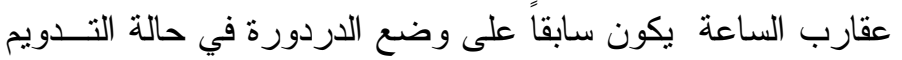
مع عقارب الساعة وذلك للأنبوبتين الطويلة و القصيرة. 